\title{
POLYMECHANOS GHENOS - THE FATE OF THE CYBERNETIC WEST, BETWEEN TECHNOLOGY AND HUMANITIES
}

\author{
Di Trapani Giovanni ${ }^{1}$, Tafuri Ranieri Maria ${ }^{2}$
}

Researcher at IRISS/CNR (Istituto di Ricerca su Innovazione e Servizi per lo Sviluppo/Consiglio Nazionale delle Ricerche).

Adjunct professor of Tourism Statistics and Economic Statistics at Unipegaso.

2 Expert of the discipline and member of the exam commission concerning the teaching of Economic Statistics (SECS-S / 03) - Law Degree Course - at Unipegaso.

Professor of Philosophy and History at I.S.I.S.S. "P.A. De Luca” (Avellino, Italy).

KEYWORDS: Innovation, digital revolution, Big Data Analytics, Therapeutic techniques

\section{ABSTRACT}

After a wide-ranging exploration of the critical issues triggered by the digital revolution, we intend to analyze benefits and contradictions of school culture and educational system: the theme is examined with pedagogical tools, along with the interpretative model of epistemological demystification.

Moreover, the grafting of a digital mindset in the therapeutic models developed for autism spectrum disorders has included, in fact, the purchase of a divergent gaze on the etiopathogenesis of the abovementioned syndrome, which we propose to define as a peculiar manifestation of neurological biodiversity.

Finally, the same cybernetic-computational vision ensures a preponderant role in the increasingly hegemonic affirmation of the commodity-form and can be intended as a key to unambiguously understand the globalized world, by means of economic profiling made available by the paradigm of Big Data Analytics.

\section{INTRODUCTION}

Ethos anthròpoi daimon, asserted the great Heraclitus. If the philosopher of Ephesus had placed his farsighted and prophetic gaze on the weltanschauung of the Faustian West (as from the Spenglerian lexicon), he would have rectified his famous maxim by converting it this way: tèchne anthròpoi daimon: there is no doubt, in fact, that the civilization that characterizes the post-modern, and which emerges in the aftermath of the brief century (as denominated by Habsbawm), rooted its founding status within an imaginative frame dominated by the overshoot impetus of crossing the boundaries of the space-time horizon. And yet, an inescapable task of every thought capable of presenting itself as divergent and pro-demystifying, consists in catching the dynamics underlying these symbolic superstructures, marxianally unmasking relations of force and political-economic hypostatization of the cultural-historical becoming, understood as a not merely chaotic dimension.

First and foremost, an irrefutable element emerges: from the industrial society of surplus value to the anesthetized one of social medias, a leitmotiv that is not difficult to discern is shown, and grafted onto the common base of social control, as well as the productive profit achieved through of a domesticating containment of civil society. I.e. from the capitalist logic of proletarian exploitation to systems of technocratic inhibition referring to the apparatus of cultural industry (to borrow the Adornian syntax), the difference only consists in the greater level of surreptitious ambiguity and in the representative hypocrisy used by today's masters of cosmopolitan establishment. In fact, the same control strictly implemented at the social level on the productive forces of the proto-capitalist era through the imposition of rigid working hours aimed at achieving the greatest possible profit, is manifested today, more subtly, with the containment of the political activism and rebel public opinion by means of the meanderings of virtual social-medias, able to canalize on established and programmatically directed tracks insurrectional pushes considered pernicious or conflicting energies. And intellectual anesthesia is complementary to a constant and dizzyingly increasing activity of economic profiling, which is very invasive and now also performed at home with the most recent software developments of operating systems for the statistical determination of television preferences; in fact, the pervasive and reticular withdrawal of personal information obtained through the use of digital devices and social networks appears so evident that it would be unnecessary to spend more words.

Therefore, in this study, we intend to proceed to the examination of the different and controversial outcomes deriving from the implementation of the “cybernetic gene" in the Western man's DNA.

\section{THE PEDAGOGICAL AND DIDACTIC TECHNE IN THE "DIGITAL SCHOOL"}

The situation, in the words of the Italian aphorist Ennio Flaiano, appears to be dramatic, but not serious, when we consider how the scaffolding of hedonistic and consumerist thinking is penetrated and institutionalized also in the context of national 
education systems. This educational havoc is presented by pseudo-scientific schematizations of pedagogical thought as the most desirable and elevated method of formation of the young minds, i.e. as the most useful for their complete subjugation: which is not a reason for surprise indeed, as another indefectible and favorite tool of the established system, is precisely the conversion of the dominant ideology into a unique ideology, presented as the best among those that can be conjectured.

From an applicative point of view, this renewed didactic paradigm finds its most obvious epistemological declination in the recent Italian legislative process, able to semantically turn the school from educational agency into consumer company whose main purposes consist in deplorable commercial policies: the alleged digitalization of teaching environments and strategies, aimed at the construction of an inclusive and reticular way of learning, has been translated, as a matter of fact, into a constant decline of educational goals.

First of all, at the level of educational systems and under the pedagogical profile, we must highlight some anachronistic idiosyncrasies which, in the context of the articulated problematic of learners with special educational needs, make the substantial transition from integrative to inclusive semantics very difficult. In this regard, the guidelines of 2009 set forth by the Italian Ministry of Education are noteworthy for a remarkable hermeneutical oscillation not only in the linguistic form (one still speaks of "integration"), but also in the heuristic substance: if the first part the aforementioned guidelines is limited to a commented synopsis on the coeval legislation, with the addition of ICF biopsychosocial paradigm, in the second and third part we pass, respectively, to organizational aspects and to school inclusive dimension. As for the latter, it transpires unequivocally that the center of gravity of the pedagogical and didactic organization is still understood in terms of integration rather than inclusion. First of all, the third part of the guidelines highlights the essential role of the head teacher in conferring a managerial inspiration on the inclusive educational institution, and clearly underlines the nature of disability, as stated in the preface: "The head teacher is the guarantor of the educational offer that is planned and implemented by the educational institution"; the educational planning must be "inclusive" because disability is "an event" (Prot. 4/8/2009 n. 4274). Nevertheless, when the text specifies the organizational tasks of the head teacher, including the promotion of staff training updating, the activation of inclusive projects, the involvement of families in planning the inclusive education, the link between the different territorial realities and the removal of any architectural or sensory-perceptive barriers, it does not mention the need to rethink in a proactive way the role of the specialized teacher in his task of relational bridge between the pupil with disability and the class group and between himself and other teachers. In the definition of curricular paths and in the construction of personalized didactic timetables, the ultimate goal remains, in fact, the integration and not the inclusion of the student with SEN. Therefore, a wide-ranging comprehension of the inclusive pedagogical dimension is deficient and still confined in a limited and limiting way within the semantic and conceptual borders of the old model of integration. Instead, a perspective of wider views and greater propulsive efficacy should be suggested in order to realize a more profound and original vision of the concept of inclusion, which presupposes a gravitational extension of the biopsychosocial paradigm to all the subjects involved in the same educational relationship, because each of them bears different needs both in psycho-affective terms and in a learning perspective.

After the promulgation of law 170/2010, which regulates the complex subject of specific learning disabilities in schools, followed by the relevant ministerial directive of $12 / 7 / 2011$, Italy also incorporates and implements in its legislative corpus the Anglo-Saxon "label" of special educational needs, an expression which has caused a lot of pedagogical improvisations: in other words, the real consequence of the ministerial directive dated $12 / 27 / 2012$, i.e. the circular $6 / 3 / 2013$ n. 8 , which had the illusion to build a truly inclusive school, was the reception of some simplistic and trivializing slogans not aimed to the inclusion of certified learning difficulties, but to the dramatic reduction of educational targets, which has led to an increase of critical issues within the high school courses; therefore, the need for a unitary criterion of school disadvantage, also through the assimilation of the ICF classificatory paradigm, is far from representing the longed-for abatement of any curricular and learning discrimination: it marked, on the contrary, the umpteenth step backwards, because it totally forgets the inclusive nature of the school system. As for the most recent developments in the Italian parliamentary legislation, it is better to stay within a purely speculative framework, as it appears clear that the failure in recognizing the authentic value of disability, intended as a special and precious divergence, corresponds to the very serious lowering of the qualitative parameters in all the orders and degrees of education, whose best resources are systematically martyred through the instrument of standardized national surveys, or evaluative tests made of statistical and conformist soul, in the logic of "if you are wrong you are out" (as appropriately and recently stigmatized by the students themselves). And even the high-sounding "National Digital School Plan", milestone of the law 107/2015, turned out to be a trap invented in order to hide an indecorous social, cultural and professional framework in which the renamed "School 3.0", rather than utilizing multimedia teaching and laboratory models, is forced to deal, sometimes, with much more structural and building deficiencies.

In this context, the role of the support teacher, who has suffered significant changes over the decades in the attribution of functions and competences, in co-management and curricular co-planning, is still seriously compromised by ruthless social preconceptions and by a chaotic school system (made of disputes and contradictory situations) which remains incapable of giving reason to its irreplaceable and not delegable task. Given the worrying (and sometimes discouraging) situation outlined above from a sociocultural point of view, the real problems and the actual risks that a support teacher has to deal with during his teaching practice and professional activity, are sadly undervalued or worse marginalized: in fact, rather than taking care of students with disabilities, the greater 
attention of Italian professors (unfortunately induced, or worse desired by the "school market") seems to be aimed at legal recourses to achieve the coveted teaching post or at digital masters to scale the school rankings. From what has been said, the educational and psycho-pedagogical needs of the student with disabilities are often overshadowed by the public education system itself: and that goes without saying because the greatest lack of professorships is exactly related to support assignments. And more and more the relevance of didactic continuity, especially for students with difficulties, appears to be a distant mirage, a torch at the bottom of a rhetoric tunnel, ultimately an utopian hope sacrificed on the altar of marketing strategies and capitalistic finalities (Tafuri R.M., 2019).

\section{THERAPEUTIC TECHNIQUES IN THE PSYCHIATRIC FIELD}

On the other hand, the discourse is notably different if it is shifted from the disastrous didactic-pedagogical area to the medical-scientific one, where the implementation of a new paradigmatic instruments, related to the polymechanos character of Western chromosome, has undoubtedly led to renewed therapy techniques for students suffering from psychiatric pathologies. For example, in the articulated panorama of autistic spectrum syndromes, as indexed in the fifth edition of the Diagnostic-Statistical Manual of Mental Disorders, a specific section relates to the so-called area of limited functioning subjects. The last edition of the DSM has in fact archived the psychometric paradigm of the IQ both in the differential diagnosis and in the rehabilitation prognosis, directing the respective criteria towards an approach based on the biopsychosocial model cleared by the aforementioned ICF. In this perspective, a predominant role is played by the possibility of the subject to relate to the social context of reference, to optimize sociocommunicative capacities, to envisage an adequate and satisfactory insertion into the world of work. In fact, as amply corroborated by scientific literature on the subject, it is the environmental interferences (often associated with the psychological, communicative and affective condition of pre and intra-scholastic life) to constitute a decisive element in the onset or in the decrease of the symptoms related to the autistic spectrum. Consequently, from a prognostic point of view, an adequate rehabilitation in cases of limited functioning autism is primarily associated with a multifactorial therapy aimed at reinforcing the bonds of socio-communicative empathy that are precociously inhibited by an excessive systematizing attitude: in such a perspective, it is necessary to synoptically combine the vision of autism referred to psychodynamic hermeneutics, organic assumptions borrowed from the pathological neurobiology of the nervous system, but also the paradigm of humanistic and existential psychology connected to gender differences and to the digital context in which the patient finds himself immersed. From what has been said, the multifactorial orientation of rehabilitation techniques, which act not only in a psychotherapeutic manner and with the strategies of behaviorist theory, but also with the contributions of digital tools required by a biopsychosocial approach, is nothing else but the mirror of a complex etiological Gordian knot, still not adequately untangled, concerning the articulated problem of autistic syndromes.

Ultimately, it is inconceivable to eradicate the therapeutic model related to autism spectrum pathologies from its epistemological frame of reference: in the face of a plethora of such differentiated symptoms, grafted onto diagnostic schematizations that remain controversial, it is necessary to connect the presumed neurological anomaly to an interpretative and experimental trajectory capable of overcoming the same physiological horizon; in this perspective, confining autism to the pages of psychiatric manuals may prove to be, in the near future, the consequence of an incorrect paradigmatic configuration of a particular brain structure, full of originality and digitally assorted peculiarities, and only conventionally considered by analytical models of medical science as a pathology. Because of this, there are no universally valid rehabilitative strategies, since the best therapy for autism spectrum syndromes remains, even today, the etymologically understood "empathizing" (from ancient Greek word empatheia), i.e. accepting all the diversities as a preliminary action in order to take care: this logic appears sometimes to be different from the post-modern ideals, according to which diversity should be absorbed in the deathly embrace of the psychologically correct category, as set by the hedonistic spirit of the globalization: capitalist ethics, in fact, seems to have no qualms in abhorring representations of anthropological biodiversity and neurological differences, which, on the contrary, always bring unique and unrepeatable personalities. (Tafuri R.M., 2019).

\section{THE BIG DATA ANALYTICS ALGORITHM AND ITS IMPLICATIONS ON A GLOBAL ECONOMIC CONTEXT}

Having ascertained the contradictions of technocratic hermeneutics in the psycho-pedagogical universe, the other side of the coin can be identified, instead, in the dispositional and utilitarian character (as from Karl Popper's axioms) of the statistical-economic algorithms made necessary by the digital revolution. In fact, in the last 15 years, advances in computer technology and the explosion of new sources of digital data supply have widened and reinvented economic approaches, especially in the insurance sector (Koutsomitropoulos and Kalou 2017). Big Data Analytics in the insurance industry, as evident, overcomes the traditional boundaries of actuarial science. Actuaries, who use advanced theories of financial mathematics to analyze and forecast future risk costs, have always been the main elements of insurance activity: the investigations carried out by actuaries are considered of fundamental importance for the survival and profitability of an insurer. But one of the main consequences of an approach referred to Big Data Analytics is fully verifiable, for example, in car insurance and in particular in the claims management. As a matter of fact, the companies did, in fact, rely on the mere evaluation of the historical claims data: i.e. on internal data. Recently, however, insurers are increasingly incorporating reliability ratings based on new analysis elements into their analyzes: user behavior. These ratings are based on empirical evidences that highlight the fact that the 
"best" customers are also the drivers that have proved themselves most reliable. The use of risk ratings in private insurance policies is, however, a very controversial issue for the sector as the addition of third-party behavioral sources represents a significant step forward compared to traditional claims data or demographic and physical ones analyzed in the past by insurers (Batty et al. 2010).

In recent times, a new wave of innovation and advanced Analytics applications is emerging in all types of insurance products, but also in the business functions of the companies. Although Life insurers and the ones working in the Non-Life / Accident business lagged behind other sectors (for example the financial sector), they are catching up with the adoption of predictive models: therefore there is, slowly, an optimization of business processes, in particular of the marketing ones (Bradlow et al. 2017). The overall effect of these developments can be found in terms of:

- Greater depth and breadth of Big Data Analytics potential;

- Significant improvements in management processes;

- Development of new products.

Although for insurance companies the impulse to invest in Analytics technology has never been so thriving, the challenges of business value creation should not be underestimated. Technology changes, as everyone knows, much faster than people. An obstacle among all is, in fact, the slow process of accepting new technologies for most insurance companies. To this form of indolence of the insurance companies is added an inability to connect the behaviors of the people "adduced" by the new technologies with forms of innovative insurance coverage. Consumers have achieved high levels of quality in the use of mobile services thanks to the policies adopted by companies in other economic sectors and mainly by industries that have more experience in the so called mobile (Di Trapani G., 2018).

From what has been said, the adoption of Big Data by the insurance sector is still in an embryonic stage; but it is possible to foresee that these technologies can play a more than decisive role in the near future: if the insurers continue not to pay proper attention to Big Data, they will risk losing a lot about the opportunities to understand consumers' behavior and also the existing potentialities in the world (Di Trapani, 2018). Information Technology (IT) creates a lot of new opportunities for improvement that were impossible in the past: today - in the era of Big Data - an enormous amount of information is available for all types of industrial applications (Coviello et al. 2017). The extraction first, and then the use of the information deriving from these enormous databases, is not easy since these data are linked to real-time events, but, if properly managed, they can be used for reprogramming or planning new activities through appropriate applications that can contribute to the reduction of risk levels and to improve the profitability and efficiency of the business system. Big data is, as widely shared in literature, an emerging theme that is attracting the attention of many researchers and professionals, and new services are thus spreading: among all, the clouds that can be considered as a huge "warehouse" of information that becomes a source of data. The phenomenon of information explosion, or rather "data deluge" (The Economist 2010), finds its sap in the volume of information coming from a variety of sources and from its growing generation rate (Di Trapani 2008). In a recent report it was predicted that, starting from 2005 and until 2020, the global data volume will grow exponentially: in fact, it will go from the current 130 exabytes to 40000 exabytes: huge volumes with unprecedented growth rates that double every two years (IDC 2013). The term BigData has been coined recently and well represents the profound meaning of this trend of data explosion: a recent study states that the potential value of data can easily be estimated at 100 billion dollars and could be able to generate a global business of between 450 and 750 billion dollars by 2030 (McKinsey \& Company 2011).

\section{CONCLUSION}

Finally, beyond the undeniable and inalienable horizons of possibilities that the statistical-digital models are capable to express, the plethora of frontiers that homo oeconomicus is about to cross in the near future is still poised on the labile border between the utopian and dystopian, as predicted in Orwell's "1984". And yet, the fulfillment of our cybernetic agitation, of our digital and multiform genome, will turn towards paths that are not only computationally traced, but also spiritually marked, only if the ancient humaneness of Greek origin and of Heraclitean definition is not forgotten, for it finds in èthos and not in tèchne its main and indelible root. 


\section{REFERENCES}

1. Batty, Mike et al. 2010, Predictive Modeling for Life Insurance, "Ways Life Insurers Can Participate in the Business Analytics Revolution" 1-29.

2. Bradlow, Eric T., Manish Gangwar, Praveen Kopalle, and Sudhir Voleti, 2017, The Role of Big Data and Predictive Analytics in Retailing, "Journal of Retailing" 93(1):79-95.

3. Coviello A., D’Antonio C., De Gaetano A., Di Trapani G., Trocciola A., 2017, L'nnovazione per la crescita dei servizi assicurativi e del Risk Management, in http://www.innovationvillage.it/it/programma/.

4. Di Trapani G., 2008, L'evoluzione dell'Offerta dei prodotti assicurativi "on-line”, in "L'utilizzo delle tecnologie avanzate nel settore assicurativo: l'e-insurance”, a cura di Coviello A., Torino, Giappichelli Ed.

5. Di Trapani G., 2017, Le insurtech: nuove sfide ed opportunità per le compagnie assicurative, "Rivista elettronica di diritto, economia, management", N. 3 -2017, p. 80.

6. Di Trapani G., 2018, Big data driven marketing: innovazione e cambiamento nel settore assicurativo, "Rivista elettronica di diritto, economia, management", N. 3 - 2018, p. 81.

7. Di Trapani G., 2018, Il ruolo della big data analytics nella trasformazione digitale dei servizi assicurativi, "Rivista elettronica di diritto, economia, management", N. 3 - 2018, pp. 93-94.

8. International Data Corporation, 2013, The digital universe in 2020: Big Data, Bigger Digital Shadows, and Biggest Growth in the Far East — United States, https://www.emc.com/collateral/analystreports/idc-digitaluniverse-united-states.pdf.

9. Koutsomitropoulos, Dimitrios A. and Aikaterini K. Kalou. 2017, A Standards-Based Ontology and Support for Big Data Analytics in the Insurance Industry, ICT Express 3(2):57-61.

10. McKinsey \& Company, 2011, Big data: The next frontier for innovation, competition, and productivity, McKinsey Global Institute, doi:10.1080/01443610903114527.

11. Tafuri R.M., 2019, Dalla formazione ex-ducativa all'inclusione post-globante: una brachilogica "considerazione inattuale" sullo status aporetico dell'odierna epistemologia normativa scolastica, to be reviewed and published in "RTH" ("Research Trends in Humanities").

12. Tafuri R.M., 2019, Tecniche per la riabilitazione psichiatrica. Studio multifattoriale sulle strategie riabilitative per i disturbi dello spettro autistico a funzionamento limitato, in "JAHC" ("Journal of advanced health care"), n.s. 1 - 2019.

13. The Economist, 2010, The data deluge, http://www.economist.com/ node/15579717.

\section{LEGISLATIVE REFERENCES (IN CHRONOLOGICAL ORDER)}

1. Prot. 4/8/2009 n. 4274: Linee guida sull'integrazione scolastica degli alunni con disabilità.

2. Law 8/10/2010, n. 170: Nuove norme in materia di disturbi specifici di apprendimento in ambito scolastico.

3. Ministerial Directive 12/7/2011 n. 5669: Linee guida disturbi specifici di apprendimento.

4. Ministerial Directive 27/12/2012: Strumenti d'intervento per alunni con bisogni educativi speciali e organizzazione territoriale per l'inclusione scolastica.

5. Ministerial Circular 6/3/2013 n. 8: Strumenti d'intervento per alunni con bisogni educativi speciali e organizzazione territoriale per l'inclusione scolastica. Indicazioni operative.

6. Law 13/7/2015 n. 107: Riforma del sistema nazionale di istruzione e formazione e delega per il riordino delle disposizioni legislative vigenti. 